\title{
Cardiac magnetic resonance imaging in the current practice
}

\author{
Ressonância magnética cardíaca na prática atual
}

\section{Flávia Pegado Junqueira ${ }^{1}$}

Because of increasing scientific and technological advances, the use of cardiac magnetic resonance imaging (MRI) keeps exponentially increasing over at least 30 years, and for many years has been utilized as a routine in the clinical practice both on outpatient and emergency/inpatient bases, particularly in centers where the clinical staff could remain updated, following the advances in the technology applied to cardiac imaging.

Even being the most recent diagnostic method in terms of cardiac imaging if compared with scintigraphy and echocardiography, cardiac MRI has its high value demonstrated as a one-stop-shop imaging method with innumerable advantages over other methods because of its high spatial resolution associated with capacity of tissue characterization by means of conventional and contrast-enhanced MRI sequences. With such characteristics, morphology, biventricular function, perfusion at rest or under pharmacological stress for investigation of ischemia, areas of injury and myocardial viability can be evaluated in a single procedure. Additionally, cardiac MRI is an increasingly promising method in the assessment of coronary arteries.

New high-field 3T magnets have added even higher spatial resolution and tissue contrast, improving the imaging quality in procedures such as myocardial perfusion scan, so the definitive inclusion of this method in the algorithm of cardiac evaluation is inevitable.

Cardiac MRI is currently considered a gold standard to quantify cardiac mass and volume, because of its low variability, high reproducibility and better accuracy when compared with other imaging methods utilized in cardiology ${ }^{(\mathbf{1 , 2})}$.

In Brazil, the first guideline on the utilization of such method was published in $2006^{(3)}$ and the number of quali-

1. Fellow PhD degree, Hospital Universitário Clementino Fraga Filho (HUCFF), Radiologist at Delboni-Auriemo and Lavoisier - DASA-SP and Prolaudo Telerradiologia, Rio de Janeiro, RJ, Brazil. E-mail: junqueira.fp@gmail.com. fied centers in the country has increased over the last years. However, few or almost no scientific data are available about the clinical utilization of cardiac MRI in Brazil. Currently, an extensive trial is underway ${ }^{(4)}$ in order to aid in the definition of normality parameters for ventricular function in the Latin American population, so it is no more necessary to rely exclusively on North-American or European parameters.

In the present issue of Radiologia Brasileira the readers can find an interesting study developed by Barranhas et al. ${ }^{(5)}$, whose objective was to describe the profile of a population studied with cardiac MRI, according to indications and origin of the requested studies. At the end of the study, the authors observed that the population submitted to cardiac MRI is quite heterogeneous, covering all the age ranges and a wide spectrum of clinical indications. The most prevalent indications included investigation of myocardial ischemia, followed by investigation of myocarditis, arrhythmogenic left ventricular dysplasia and myocardial viability, among others. However, and not less important, the authors observed a high number of procedures to investigate several types of dilated and hypertrophic cardiomyopathies, arrhythmogenic and congenital diseases, besides cardiac tumors.

\section{REFERENCES}

1. Nacif MS, Marchiori E, Rochitte CE. Ressonância magnética cardíaca para radioablação de fibrilação atrial: protocolo e técnicas de quantificação do volume atrial esquerdo. Radiol Bras. 2009;42:370.

2. Omoumi $P$, Métais JP, Bertrand $P$, et al. Left and right ventricular volumetry and ejection fraction with MRI: segmentation criteria and interobserver reproducibility. J Radiol. 2010;91:769-78.

3. Rochitte CE, Pinto IM, Fernandes JL, et al. I cardiovascular magnetic resonance and computed tomography guidelines of the Brazilian Society of Cardiologia Executive summary. Arq Bras Cardiol. 2006;87:e48-59.

4. Latin American Multicenter Cardiovascular Magnetic Resonance Reference Study. [acessado em 16 de janeiro de 2014]. Disponível em: http://www.clinicaltrials.gov/ ct2/show/record/NCT01030549.

5. Barranhas AD, Santos AASMD, Coelho-Filho OR, et al. Ressonância magnética cardíaca na prática clínica. Radiol Bras. 2014;47:1-8. 